\title{
Changing trends in liver transplantation indications in Saudi Arabia: from hepatitis C virus infection to nonalcoholic fatty liver disease
}

\author{
Saleh A. Alqahtani ${ }^{1,2^{*}}$, Dieter C. Broering ${ }^{1}$, Saad A. Alghamdi , Khalid I. Bzeizi ${ }^{1}$, Noara Alhusseini ${ }^{3}$, \\ Saleh I. Alabbad' ${ }^{1}$, Ali Albenmousa', Nasreen Alfaris ${ }^{4}$, Faisal Abaalkhail ${ }^{3,5}$ and Waleed K. Al-hamoudi,6
}

\begin{abstract}
Background: Several trend analyses on liver transplantation (LT) indications have been published in the U.S. and in other countries, but there are limited data on LT indication trends in Saudi Arabia (SA), especially since the availability of direct-acting antivirals (DAAs) treatment for hepatitis $\mathrm{C}$ virus (HCV). This study aimed to analyze trends in the frequency of $L T$ indications among $L T$ recipients in SA over a 19-year period and examine associations between etiologic-specific trends and clinicodemographic characteristics.
\end{abstract}

Methods: This retrospective study analyzed clinical and surgical data of adult patients $(n=1009)$ who underwent LT at the King Faisal Specialist Hospital \& Research Center (Riyadh, SA) between 2001 and 2019. Spearman's rank correlation, Poisson regression, and Joinpoint regression analysis were employed to assess changes in LT etiologic trends.

Results: In the first period (2001-2010), the main LT indications were HCV (41.9\%) and hepatitis B virus (HBV) (21.1\%), but nonalcoholic steatohepatitis (NASH) (29.7\%) surpassed HCV (23.7\%) as the leading LT indication in the second period (2011-2019); and the trends were significant in correlation analyses [incidence rate ratio (IRR) $=1.09(1.06-1.13)$ for NASH; IRR = 0.93 (0.91-0.95) for HCV]. In the Joinpoint regression analysis, increases in NASH from 2006 to 2012 (+ 32.1\%) were statistically significant, as were the decreases in HCV from 2004 to 2007 (-19.6\%) and from 2010 to 2019 (-12.1\%). Similar patterns were observed in LT etiological comparisons before and after the availability of DAAs and within hepatocellular carcinoma stratifications.

Conclusions: Trends in the epidemiology of LT indications among LT recipients in SA have changed over a 19-year period. Most notably, NASH has eclipsed HCV in the country due to the effective treatment strategies for HCV. These trends in NASH now need an aggressive public health response to minimize and avert future onset of additional clinical and economic strains on health care systems and LT centers in SA.

Keywords: Liver disease, Liver transplantation, Nonalcoholic steatohepatitis, Saudi Arabia, Trend analysis

*Correspondence: salalqahtani@kfshrc.edu.sa

1 Liver Transplant Center, King Faisal Specialist Hospital \& Research Center, Riyadh, Saudi Arabia

Full list of author information is available at the end of the article

\section{Background}

Worldwide, chronic liver disease (CLD) is estimated to cause 2 million annual deaths [1]. Among those who die from CLD, half die from cirrhosis-associated complications, and the other half die from viral hepatitis (VH) or hepatocellular carcinoma (HCC). Currently, liver transplantation (LT) is the only curative option for patients living with end-stage liver disease (ESLD) 
[2]. Before 2014, chronic hepatitis C virus (HCV) infection was the most common indication for non-HCC LT listing in the United States (U.S.) [3]. The advent of direct-acting antivirals (DAAs) has revolutionized treatment for $\mathrm{HCV}$, reduced progression to ESLD in a significant number of patients living with $\mathrm{HCV}$, and lessened the need for LT in patients living with $\mathrm{HCV}$ $[4,5]$. As a result, $\mathrm{HCV}$ was replaced by alcoholic liver disease (ALD) in 2015 as the primary listing indication for LT in the U.S. (19.7\% vs. $28.5 \%$ of non-HCC LT listing, respectively) [3]. Interestingly, $\mathrm{NASH}$ and ALD continue to increase in prevalence among LT candidates, with NASH and ALD accounting for $28.1 \%$ and $37.7 \%$ of the total number of listings without HCC in 2019, which were 5.4 times and 2.2 times higher than the 2002 values, respectively [3]. Similar trends have been observed in Europe. The 2018 Annual Report of the European LT Registry noted a sharp decline in VHrelated indications over the last 50 years, and the report projected that NASH will be the leading indication for LT in Europe within the next decade [6].

$\mathrm{NASH}$ is the most severe form of nonalcoholic fatty liver disease (NAFLD) [7]. The main risk factors for NAFLD are obesity, type 2 diabetes mellitus (T2DM), dyslipidemia, and insulin resistance [8]. As the worldwide prevalence of obesity has tripled from 1975 to 2016 [9], the current obesity pandemic will likely accelerate worldwide increases in the prevalence of NAFLD, and consequently, NASH [10]. Such an undesired hike in prevalence may cause a substantial rise in liver-related complications and escalate the need for LT [11]. Sex dimorphism is reported in the NAFLD prevalence and associated outcomes, highlighting the need for detailed investigations of sex differences in these patients [12]. Additionally, NAFLD is found to cause fatal and non-serious cardiovascular disease (CVD) and its associated adverse outcomes [13]. Patients with liver cirrhosis develop pre-LT electrocardiographic abnormalities with symptoms like lengthened QTc interval and ST depression; they are 14-times more likely to develop a post-LT CVD event [14]. The odds of developing serious CVD events are reportedly high in patients with severe NAFLD, prompting clinicians to consider NAFLD as an independent risk factor for CVD events [15-17]. Biomarkers of liver fibrosis correlate CVD risk scores in patients with biopsyconfirmed CLD, stressing the need for continuous testing of liver disease status while attempting to stratify CVD events [18]. Likewise, co-screening for T2DM in NAFLD patients is also recommended, which would allow for early interventions [19]. A registry-based study found that LT recipients for NASH pose a higher risk of developing de novo T2DM, indicating the presence of preexisting metabolic syndrome alongside NASH [20].
In Saudi Arabia (SA), the prevalence of obesity is approximately $38 \%$, and it is projected to reach $45 \%$ by 2025 [9]. Given the high prevalence of obesity in the Middle East and that other countries have observed rapid changes in LT indications, there is a need to examine current trends in LT indications in SA. Cirrhosis due to sclerosing cholangitis was the indication for the first-ever LT in SA [21], but since then, there have been dynamic changes in LT indications in the country. Several trend analyses on LT indications have been published in the U.S. and other countries [6,22-24], but there are limited data on LT indication trends in the Middle East, especially after 2014, when the DAAs became available in SA for treating HCV [25]. It is important to characterize and to stay abreast of probable changes in LT indication trends to mobilize and support public health and health policy resources for optimal reduction and management of disease burden and the associated complications in the context of LT. In this retrospective study, we analyzed trends in the frequency of LT indications among LT recipients in a single-center in SA over a 19-year period and examined associations between etiologic-specific trends and clinicodemographic characteristics.

\section{Methods \\ Study design}

In this single-center, retrospective study, we collected and analyzed anonymized clinical and surgical data of adult patients who underwent LT at the King Faisal Specialist Hospital \& Research Center (KFSHRC, Riyadh, SA) between 2001 and 2019. All adult patients who underwent LT $(n=1009)$, irrespective of etiology, were included in the analysis.

\section{Outcomes of interest}

Primary outcomes of interest were (1) the most frequent LT indications over the full study period (2001 to 2019) and between two sub-periods (2001 to 2010 vs. 2011 to 2019), (2) year-on-year trends of the most frequent LT indications, and (3) ways in which the two sub-periods and pre- and post-DAA eras (pre-2014 vs. 2014 to 2019, DAAs were not widely available in SA until 2014) differed in patient characteristics and LT indications, respectively. Secondary outcomes of interest were the most frequent LT indications among patients with and without HCC, and year-on-year trends of the most frequent LT indications stratified by HCC status. Indications were extracted from electronic medical records and grouped into 8 categories: NASH, HCV, hepatitis B virus (HBV), Wilson's disease, primary sclerosing cholangitis (PSC), autoimmune hepatitis $(\mathrm{AIH})$, schistosomiasis $(\mathrm{SCH})$, and other (i.e., "other" was a composite variable created to group infrequent indications ( $<2 \%$ of all LTs). 


\section{Variables}

The following clinicodemographic characteristics were extracted from electronic medical records of LT recipients from 2001 to 2019: age, sex, body mass index (BMI), waitlist times, donor sources, Model for EndStage Liver Disease (MELD) scores, and HCC status.

\section{Statistical analysis}

Categorical variables were presented as frequencies and proportions and continuous variables as mean \pm standard deviation or median and interquartile range as appropriate. The Kruskal-Wallis test and the Pearson $X^{2}$ test were used to compare two periods (2001 to 2010 vs. 2011 to 2019) and patients with and without HCC on continuous variables and categorical variables. The following tests were employed to assess changes in LT etiological trends across the full study period (2001 to 2019), between pre- and post-DAA eras in SA (pre2014 vs. 2014-2019), and by HCC status: Spearman's rank correlation (percentage of patients by year for each etiology), Poisson regression (the Pearson $\chi^{2}$ goodness-of-fit test was used to assess model fit, incidence rate ratios [IRR] presented) and Joinpoint regression analysis (for exploration of any periods within the study period with significant annual percentage changes). All statistical analyses were performed using Stata (version 14, Stata Corp, College Station, Texas, U.S.) apart from Joinpoint regression analysis, which was performed using the Joinpoint Regression Program.

\section{Ethical approval and informed consent}

On December 3, 2019, the Institutional Review Board of KFSHRC (Riyadh, SA) approved this study and waived the need for informed consent due to the retrospective and anonymous nature of the study (Approval Number: RAC 2,171,177). This study was carried out in accordance with the World Medical Association (WMA) Declaration of Helsinki (adopted: 1964; last amended: 2013) and the WMA statement on measures for the prevention and fight against transplant-related crimes (adopted: October 2020).

\section{Results}

Demographic and clinical characteristics of LT recipients

Among those who underwent LT between 2001 and 2019 (Table 1), the median age was 55 (45-62) years, the median BMI was 26.1 (22.9-30.5), and the majority were male $(62.8 \%)$. The most prevalent LT etiologies were HCV (28.4\%), NASH (24.6\%), and HBV (22.2\%).

\section{Trends in LT etiology}

In the first period (2001-2010), the main LT indications were $\mathrm{HCV}(41.9 \%)$ and $\mathrm{HBV}$ (21.1\%) (Fig. 1a). In the second period (2011-2019), NASH (29.7\%) surpassed HCV (23.7\%) as the leading LT indication, while other indications remained relatively stable in both periods. In addition, since 2016, NASH has remained the leading LT indication (Fig. 1b). Across the full study period (2001-2019) (Table 2), the decline in HCV and increase in NASH as the leading LT etiology was statistically significant in correlation analyses (IRR $=1.09$ [1.061.13] for $\mathrm{NASH}$; IRR $=0.93$ [0.91-0.95] for $\mathrm{HCV})$. In the Joinpoint regression analysis, increases in NASH from 2006 to 2012 (32.1\% increase) were statistically significant, and decreases in HCV from 2004 to 2007 $(-19.6 \%)$ and from 2010 to $2019(-12.1 \%)$ were statistically significant.

\section{Trends in patient characteristics}

Compared to patients who underwent LT in the first period (Table 3), patients in the second period were older (median age, 50 vs. 56), had higher median MELD scores (median, 19 vs. 22), longer waitlist times (median, 43 vs. 82 days), and were more likely to receive LT from a living donor (27.9\% vs. $74.5 \%)$ and to have HCC (21.5\% vs. $30.2 \%)$.

\section{Trends in LT etiology before and after the availability of DAAs}

During the pre-DAA era (i.e., pre-2014, before the availability of DAAs in SA) (Fig. 2), HCV (39\%) was the leading LT etiology, followed by HBV (22\%). However, in the post-DAA era (i.e., 2014-2019, during the availability of DAAs in SA), NASH emerged as the leading LT etiology, followed by HBV (23\%). Comparing LT etiologies before and after the availability of DAAs in SA (Table 4), increases in NASH were statistically significant (17.6\% to $30.3 \%$, IRR $=1.72[1.32-2.25])$, as well as the decreases in $\operatorname{HCV}(39.1 \%$ to $19.7 \%, \mathrm{IRR}=0.50$ [0.40-0.64]). There were no differences in statistical significance between periods for other etiologies.

\section{Trends in LT etiology by HCC status}

Compared to patients without HCC (Table 5), patients with $\mathrm{HCC}$ were more likely to be male (60.0\% vs. $70.2 \%)$ and older (median, 53 vs. 60), have higher BMI (median, 25.7 vs. 26.6) and MELD (median, 21 vs. 22) scores. Among patients with $\mathrm{HCC}$ (Fig. 3a), HCV and HBV were the leading LT etiologies for both periods (2001-2010: 60\% and 35\%; 2011-2019: 40\% and 30\%, respectively). Similarly, HCV and HBV were the leading LT etiologies among patients without HCC between 2001 and 2010 
Table 1 Characteristics of LT recipients, overall and by major etiology

\begin{tabular}{|c|c|c|c|c|c|c|c|c|c|}
\hline & Overall & NASH & $\mathrm{HCV}$ & HBV & $\begin{array}{l}\text { Wilson's } \\
\text { disease }\end{array}$ & PSC & AlH & $\mathrm{SCH}$ & Other \\
\hline $\mathrm{N}$ transplants & 1009 & $248(24.6 \%)$ & $287(28.4 \%)$ & 224 (22.2\%) & $23(2.3 \%)$ & $28(2.8 \%)$ & 89 (8.8\%) & $21(2.1 \%)$ & 89 (8.8\%) \\
\hline $\begin{array}{l}\text { Age [Median } \\
(I Q R)]\end{array}$ & $55(45-62)$ & $59(53-64)$ & $58(52-64)$ & $54(48-61)$ & $23(19-29)$ & $40(32-47)$ & $32(23-45)$ & $60(57-64)$ & $34(25-54)$ \\
\hline Male [n (\%)] & $634(62.8 \%)$ & $174(70.2 \%)$ & $162(56.5 \%)$ & 167 (74.6\%) & $12(52.2 \%)$ & $13(46.4 \%)$ & 38 (42.7\%) & $21(100.0 \%)$ & $47(52.8 \%)$ \\
\hline BMI [Median] & $\begin{array}{l}26.1(22.9- \\
30.5)\end{array}$ & $\begin{array}{l}26.6(23.6- \\
32.0)\end{array}$ & $\begin{array}{l}26.9(23.9- \\
30.8)\end{array}$ & $\begin{array}{l}27.3(23.4- \\
31.3)\end{array}$ & $\begin{array}{l}22.8(20.7- \\
24.3)\end{array}$ & $\begin{array}{l}23.5(20.1- \\
27.2)\end{array}$ & $\begin{array}{l}24.2(21.6- \\
28.2)\end{array}$ & $\begin{array}{l}25.9(23.0- \\
29.3)\end{array}$ & $\begin{array}{l}23.6 \\
(20.1-27.3)\end{array}$ \\
\hline \multicolumn{10}{|l|}{$\begin{array}{l}\text { BMI group [n } \\
(\%)]\end{array}$} \\
\hline Underweight & $49(4.9 \%)$ & $6(2.4 \%)$ & $7(2.4 \%)$ & $6(2.7 \%)$ & $4(17.4 \%)$ & $4(14.3 \%)$ & 7 (7.9\%) & $0(0.0 \%)$ & 15 (16.9\%) \\
\hline $\begin{array}{l}\text { Normal } \\
\text { weight }\end{array}$ & $366(36.3 \%)$ & $78(31.5 \%)$ & $90(31.4 \%)$ & $73(32.6 \%)$ & $13(56.5 \%)$ & $14(50.0 \%)$ & $45(50.6 \%)$ & $10(47.6 \%)$ & $43(48.3 \%)$ \\
\hline Pre-obesity & $308(30.5 \%)$ & $84(33.9 \%)$ & 99 (34.5\%) & 69 (30.8\%) & $3(13.0 \%)$ & $8(28.6 \%)$ & $20(22.5 \%)$ & $7(33.3 \%)$ & $18(20.2 \%)$ \\
\hline $\begin{array}{l}\text { Obesity (class } \\
\text { 1) }\end{array}$ & 194 (19.2\%) & $52(21.0 \%)$ & $62(21.6 \%)$ & $53(23.7 \%)$ & $1(4.4 \%)$ & $1(3.6 \%)$ & $13(14.6 \%)$ & $4(19.1 \%)$ & $8(9.0 \%)$ \\
\hline $\begin{array}{l}\text { Obesity (class } \\
\text { 2) }\end{array}$ & $60(6.0 \%)$ & $15(6.1 \%)$ & $19(6.6 \%)$ & $18(8.0 \%)$ & $1(4.4 \%)$ & $0(0.0 \%)$ & $4(4.5 \%)$ & $0(0.0 \%)$ & $3(3.4 \%)$ \\
\hline $\begin{array}{l}\text { Obesity (class } \\
\text { 3) }\end{array}$ & $32(3.2 \%)$ & $13(5.2 \%)$ & $10(3.5 \%)$ & $5(2.2 \%)$ & $1(4.4 \%)$ & $1(3.6 \%)$ & $0(0.0 \%)$ & $0(0.0 \%)$ & $2(2.3 \%)$ \\
\hline $\begin{array}{l}\text { Waitlist time } \\
\text { [Median } \\
\text { days] }\end{array}$ & $49(15-139)$ & $42(20-103)$ & $58(15-160)$ & $49(15-141)$ & $75(10-110)$ & $64(24-153)$ & $36(14-156)$ & $102(42-131)$ & $49(15-155)$ \\
\hline $\begin{array}{l}\text { LT from living } \\
\text { donor [n } \\
(\%)]\end{array}$ & $628(62.2 \%)$ & 179 (72.2\%) & 159 (55.4\%) & $150(67.0 \%)$ & $10(43.5 \%)$ & $19(67.9 \%)$ & $47(52.8 \%)$ & $16(76.2 \%)$ & 48 (53.9\%) \\
\hline $\begin{array}{l}\text { MELD score } \\
\text { [Median] }\end{array}$ & $22(16-25)$ & $22(17-24)$ & $20(15-22)$ & $22(17-25)$ & $30(17-37)$ & $21(16-26)$ & $24(19-31)$ & $20(17-22)$ & $24(18-30)$ \\
\hline $\begin{array}{l}\text { HCC candi- } \\
\text { date }[\mathrm{n}(\%)]\end{array}$ & $282(28.0 \%)$ & 59 (23.8\%) & $123(42.9 \%)$ & 87 (38.8\%) & $1(4.4 \%)$ & $0(0.0 \%)$ & $2(2.3 \%)$ & $4(19.1 \%)$ & $6(6.7 \%)$ \\
\hline
\end{tabular}

LT, liver transplant; NASH, nonalcoholic steatohepatitis; HCV, hepatitis C virus; HBV, hepatitis B virus; PSC, primary sclerosing cholangitis; AlH, autoimmune hepatitis; $\mathrm{SCH}$, schistosomiasis; IQR, interquartile range; BMI, body mass index; MELD, model for end-stage liver disease; HCC, hepatocellular carcinoma
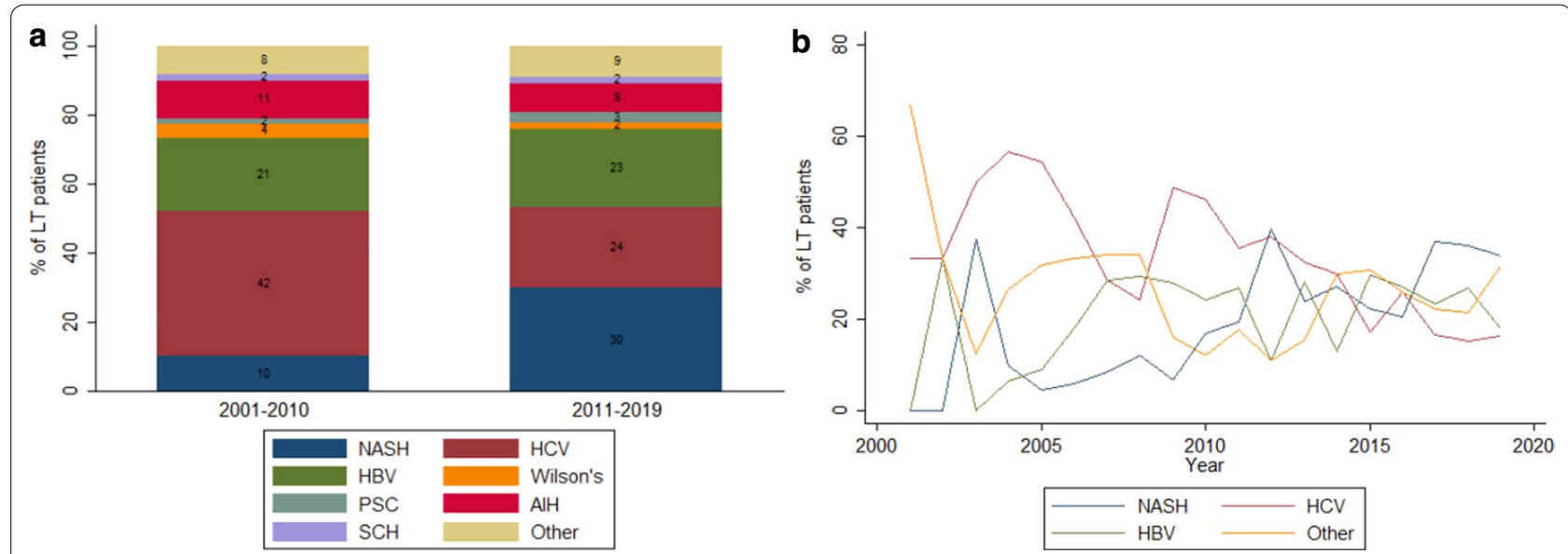

Fig. 1 a Distribution of etiologies by period: 2001-2010 and 2011-2019. b Percentage distribution of etiologies by year: 2001-2019

(Fig. 3b), but NASH (31\%) emerged as a leading LT etiology between 2011 and 2019. Stratifying patients with and without HCC within LT etiologies (Table 6), increases in
NASH among patients with and without $\mathrm{HCC}$ were statistically significant $(I R R=1.16[1.07-1.26] ; \quad I R R=1.08$ [1.04-1.12], respectively), and decreases in HCV among 
Table 2 Year-on-year trend analyses for LT etiology: 2001-2019

\begin{tabular}{|c|c|c|c|c|}
\hline & NASH & $\mathrm{HCV}$ & HBV & Other \\
\hline \multicolumn{5}{|c|}{ Spearman rank correlation } \\
\hline$P$ & 0.68 & -0.71 & 0.24 & -0.34 \\
\hline$p$ value & 0.001 & $<0.001$ & 0.318 & 0.154 \\
\hline \multicolumn{5}{|c|}{ Joinpoint regression } \\
\hline & $p<0.05$ & $p<0.05$ & $p<0.05$ & Not significant \\
\hline & $\begin{array}{l}\text { 2006-2012 } \\
\text { APC: } \\
+32.1 \%\end{array}$ & $\begin{array}{l}2004-2007 \\
\text { APC: }-19.6 \%\end{array}$ & $\begin{array}{l}2007-2019 \\
\text { APC: }-1.6 \%\end{array}$ & \\
\hline & & $\begin{array}{l}2010-2019 \\
\quad \text { APC: }-12.1 \%\end{array}$ & & \\
\hline \multicolumn{5}{|c|}{ Incidence rate ratio } \\
\hline IRR & 1.09 & 0.93 & 1.02 & 1.00 \\
\hline $95 \% \mathrm{Cl}$ & $1.06-1.13$ & $0.91-0.95$ & $0.99-1.05$ & $0.97-1.03$ \\
\hline$p$ value & $<0.001$ & $<0.001$ & 0.287 & 0.906 \\
\hline
\end{tabular}

patients with and without HCC were statistically significant over the study period (IRR $=0.94[0.90-0.98]$; $\mathrm{IRR}=0.91[0.89-0.94]$, respectively).

\section{Discussion}

We retrospectively analyzed trends in the frequency of LT indications among LT recipients in a single-center in SA over a 19-year period and examined associations between etiologic-specific trends and clinicodemographic characteristics. Several notable findings materialized from the analysis. First, NASH surpassed HCV as the leading LT indication among LT recipients in SA. In particular, NASH surpassed $\mathrm{HCV}$ for the first time in 2012; HCV regained its place for four years until 2016 when NASH outpaced HCV again and has remained the leading LT indication among LT recipients in SA. Second, declines in HCV and increases in NASH as leading etiologies over the study period were significant in correlation analyses. This trend is consistent with a recently published LT trend analysis of a large retrospective

Table 3 Characteristics of LT recipients by period: 2001-2010 and 2011-2019

\begin{tabular}{|c|c|c|c|}
\hline & 2001-2010 & 2011-2019 & $p$ value \\
\hline$N$ transplants & 265 & 744 & \\
\hline \multicolumn{4}{|l|}{ LT etiology*t } \\
\hline NASH & $27(10.2 \%)$ & $221(29.7 \%)$ & $<0.001$ \\
\hline $\mathrm{HCV}$ & $111(41.9 \%)$ & $176(23.7 \%)$ & \\
\hline HBV & $56(21.1 \%)$ & $168(22.6 \%)$ & \\
\hline Wilson's disease & $11(4.2 \%)$ & $12(1.6 \%)$ & \\
\hline PSC & $4(1.5 \%)$ & $24(3.2 \%)$ & \\
\hline $\mathrm{AlH}$ & $29(10.9 \%)$ & $60(8.1 \%)$ & \\
\hline $\mathrm{SCH}$ & $5(1.9 \%)$ & $16(2.2 \%)$ & \\
\hline Other & $22(8.3 \%)$ & $67(9.0 \%)$ & \\
\hline Age [Median (IQR) $]^{* \neq}$ & $50(37-57)$ & $56(47-63)$ & $<0.001$ \\
\hline Malet & $166(62.6 \%)$ & $468(62.9 \%)$ & 0.940 \\
\hline BMI [Median (IQR)] & $26.0(22.4-30.0)$ & $26.2(22.9-30.6)$ & 0.299 \\
\hline \multicolumn{4}{|l|}{ BMl group $[\mathrm{n}(\%)]^{\dagger}$} \\
\hline Underweight & $13(4.9 \%)$ & $36(4.8 \%)$ & 0.767 \\
\hline Normal weight & 97 (36.6\%) & $269(36.2 \%)$ & \\
\hline Pre-obesity & 81 (30.6\%) & $227(30.5 \%)$ & \\
\hline Obesity (class 1) & $47(17.7 \%)$ & $147(19.8 \%)$ & \\
\hline Obesity (class 2) & $15(5.7 \%)$ & $45(6.1 \%)$ & \\
\hline Obesity (class 3) & $12(4.5 \%)$ & $20(2.7 \%)$ & \\
\hline Waitlist time [Median days (IQR) $]^{* \ddagger}$ & $82(21-206)$ & $43(15-112)$ & $<0.001$ \\
\hline LT from living donor [n (\%)]* ${ }^{*}$ & $74(27.9 \%)$ & $554(74.5 \%)$ & $<0.001$ \\
\hline MELD score [Median (IQR)] $]^{* \neq}$ & $19(14-28)$ & $22(17-25)$ & 0.001 \\
\hline HCC candidate $[n(\%)]^{* \dagger}$ & $57(21.5 \%)$ & $225(30.2 \%)$ & 0.007 \\
\hline
\end{tabular}

LT, liver transplant; NASH, nonalcoholic steatohepatitis; HCV, hepatitis C virus; HBV, hepatitis B virus; PSC, primary sclerosing cholangitis; AlH, autoimmune hepatitis; SCH, schistosomiasis; BMI, body mass index; MELD, model for end-stage liver disease; HCC, hepatocellular carcinoma

${ }^{*}$ Significant difference between 2001-2010 and 2011-2019

${ }^{\dagger}$ Periods compared with $x^{2}$ test

${ }^{\ddagger}$ Periods compared with Kruskal-Wallis equality of populations rank test 


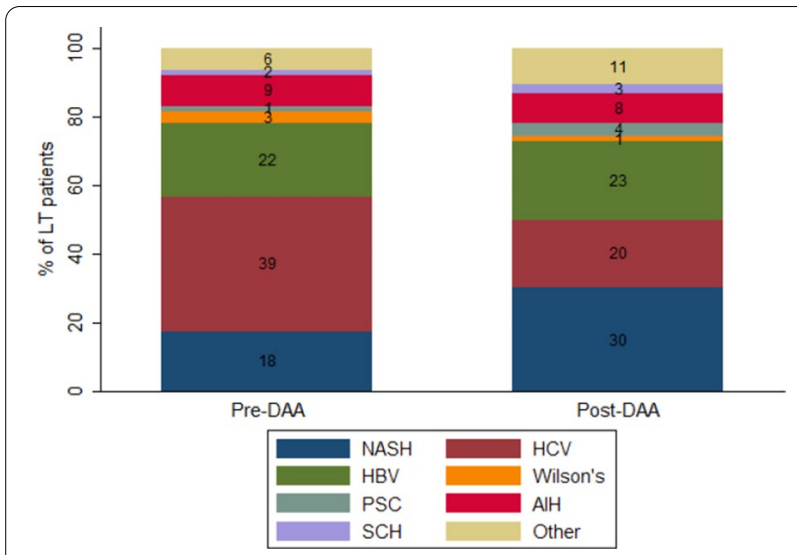

Fig. 2 Distribution of LT etiologies before (pre-2014) and after (2014-2019) the availability of direct acting antivirals (DAAs)

Table 4 Distribution of primary LT etiologies before and after the availability of direct-acting antivirals

\begin{tabular}{lllll}
\hline & NASH & HCV & HBV & Other \\
\hline Pre-DAA & $80(17.6 \%)$ & $178(39.1 \%)$ & $98(21.5 \%)$ & $99(21.8 \%)$ \\
Post-DAA & $168(30.3 \%)$ & $109(19.7 \%)$ & $126(22.7 \%)$ & $151(27.3 \%)$ \\
IRR & & & & \\
IRR & 1.72 & 0.50 & 1.06 & 1.25 \\
$95 \% \mathrm{Cl}$ & $1.32-2.25$ & $0.40-0.64$ & $0.81-1.37$ & $0.97-1.61$ \\
$p$ value & $<0.001$ & $<0.001$ & 0.686 & 0.081 \\
\hline
\end{tabular}

IRR compares pre- and post-DAA periods

LT, liver transplant; NASH, Nonalcoholic steatohepatitis; HCV, Hepatitis C virus; HBV, Hepatitis B virus; DAA, Direct-acting antiviral; IRR, incidence rate ratio; $\mathrm{Cl}$, confidence interval

Table 5 Characteristics of the LT recipients with and without HCC

\begin{tabular}{lllr}
\hline & With HCC & Without HCC & $\boldsymbol{p}$ value \\
\hline N transplants & 282 & 727 & \\
Age [Median (IQR)] & $60(54-64)$ & $53(38-60)$ & $<0.001$ \\
Male [n (\%)] & $198(70.2 \%)$ & $436(60.0 \%)$ & 0.003 \\
BMI [Median (IQR)] & $26.6(24.1-30.5)$ & $25.7(22.6-30.5)$ & 0.018 \\
BMl group [n (\%)] & & & \\
Underweight & $6(2.1 \%)$ & $43(5.9 \%)$ & 0.005 \\
Normal weight & $87(30.9 \%)$ & $279(38.4 \%)$ & \\
Pre-obesity & $107(37.9 \%)$ & $201(27.7 \%)$ & \\
Obesity (class 1) & $56(19.9 \%)$ & $138(19.0 \%)$ & \\
Obesity (class 2) & $18(6.4 \%)$ & $42(5.8 \%)$ & \\
Obesity (class 3) & $8(2.8 \%)$ & $24(3.3 \%)$ & \\
Waitlist time [Median days & $49(15-151)$ & $49(16-134)$ & 0.9038 \\
$\quad$ (IQR)] & & & \\
LT from living donor [n (\%)] & $183(64.9 \%)$ & $445(61.2 \%)$ & 0.279 \\
MELD score [Median (IQR)] & $22(15-22)$ & $21(16-27)$ & $<0.001$ \\
\hline
\end{tabular}

$\mathrm{LT}$, liver transplant; $\mathrm{HCC}$, hepatocellular carcinoma; IQR, interquartile range; $\mathrm{BMI}$, Body mass index; MELD, model for end-stage liver disease cohort in the U.S [3]. The study determined that NASH was the fastest increasing indication from 2002 to 2019, including among patients with and without $\mathrm{HCC}$, and NASH surpassed HCV and emerged as the second leading indication only after ALD in the U.S. Although ALD was ahead of NASH in the U.S., it is less frequent in SA due to socioreligious taboos and legal bans on the sale and consumption of alcohol. Nevertheless, rapid changes in NASH trends in the last two decades are unprecedented in both SA and the U.S.

Given this shift in epidemiologic trends, perhaps it is now time to consider prioritization of NASH and start applying lessons and best practices learned from HCV to NASH (i.e., public health awareness campaigns; government-supported policy recommendations-to support and facilitate early screening, identification, and linkage to care; efforts to increase access to care; and pharmacologic and staging advancements). In response to increasing changes in the epidemiology of $\mathrm{HCV}$, not long-ago, international health agencies and countries heavily burdened with HCV responsively and purposefully dedicated clinical and economic resources to combat and control HCV prevalence [26]. Likewise, efforts to prioritize and highlight the growing burden of NASH have the potential to downturn the prevalence and incidence of LT waitlisting, similar to recent downturns in the prevalence and incidence of $\mathrm{HCV}$-associated morbidity and mortality in SA and other countries abroad.

Third, the epidemiology of LT etiology trends among LT recipients changed after the availability of DAAs in SA in 2014. In pre- and post-DAA era comparisons, there were significant year-on-year increases in NASH and significant year-on-year decreases in HCV among LT recipients, and NASH ultimately eclipsed $\mathrm{HCV}$ in the current DAA era in SA. These respective findings are consistent with pre- and post-DAA LT etiology trends in Europe and the U.S $[5,27]$. Though NASH is not the leading LT etiology among LT recipients in the current DAA era in the U.S., NASH is the leading etiology for waitlisted LT patients, it is only second to HCV among LT recipients, and is steadily rising year upon year; whereas, $\mathrm{HCV}$ is declining year upon year due to effective treatment strategies, and it is quite possible that NASH in the current DAA era will overtake $\mathrm{HCV}$ as the leading indication in the U.S. in the coming years [27, 28].

Given the remarkable advancements and benefits of pangenotypic DAAs for HCV treatment, this changing trend was somewhat expected in the current study. Not only are the majority of $\mathrm{HCV}$ patients (>95\%) able to achieve virologic cure (i.e., sustained virological response [SVR]) with DAAs, but a large majority of HCV patients who achieve SVR are able to achieve cirrhosis regression $[29,30]$, and in some instances, resolve manifestations 

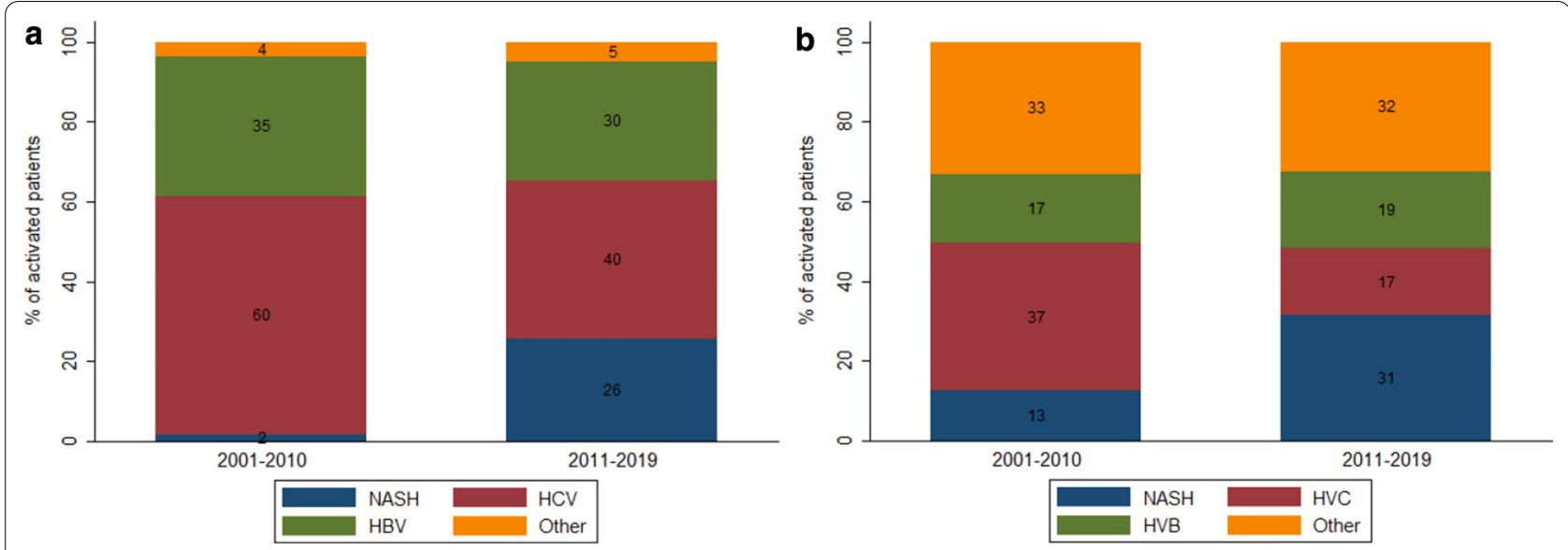

Fig. 3 Distribution of etiologies among recipients during 2001-2010 and 2011-2019 - a) With HCC. b) Without HCC

Table 6 Year-on-year trend analyses of LT etiologies by HCC status: 2001-2019

\begin{tabular}{|c|c|c|c|c|c|c|c|c|}
\hline & \multicolumn{2}{|l|}{ NASH } & \multicolumn{2}{|l|}{ HCV } & \multicolumn{2}{|l|}{ HBV } & \multicolumn{2}{|l|}{ Other } \\
\hline & With HCC & Without HCC & With HCC & Without HCC & With HCC & Without HCC & With HCC & Without HCC \\
\hline \multicolumn{9}{|c|}{ Spearman rank correlation } \\
\hline$\rho$ & 0.66 & 0.75 & -0.51 & -0.73 & 0.25 & 0.43 & 0.61 & -0.11 \\
\hline$p$ value & 0.002 & 0.000 & 0.025 & 0.000 & 0.300 & 0.069 & 0.005 & 0.652 \\
\hline \multicolumn{9}{|c|}{ Joinpoint regression } \\
\hline & $p<0.05^{*}$ & $p<0.05$ & $p<0.05^{*}$ & $p<0.05$ & NS & NS & NS & NS \\
\hline & $\begin{array}{l}\text { 2011-2019 APC: } \\
10.4 \%\end{array}$ & $\begin{array}{l}\text { 2004-2012 APC: } \\
24.5 \%\end{array}$ & $\begin{array}{l}2006-2019 \\
\text { APC: }-4.9 \%\end{array}$ & $\begin{array}{l}\text { 2010-2019 } \\
\quad \text { APC: }-12.5 \%\end{array}$ & & & & \\
\hline \multicolumn{9}{|c|}{ Incidence rate ratio } \\
\hline IRR & 1.16 & 1.08 & 0.94 & 0.91 & 1.00 & 1.02 & 1.12 & 1.00 \\
\hline $95 \% \mathrm{Cl}$ & $1.07-1.26$ & $1.04-1.12$ & $0.90-0.98$ & $0.89-0.94$ & $0.95-1.06$ & $0.98-1.05$ & $0.95-1.31$ & $0.98-1.03$ \\
\hline$p$ value & $<0.001$ & $<0.001$ & 0.002 & $<0.001$ & 0.873 & 0.414 & 0.171 & 0.768 \\
\hline
\end{tabular}

LT, liver transplant; HCC, hepatocellular carcinoma; NASH, nonalcoholic steatohepatitis; HCV, hepatitis C virus; HBV, hepatitis B virus; APC, annual percentage change; $\mathrm{IRR}$, incidence rate ratio; $\mathrm{Cl}$, confidence interval; $\mathrm{NS}$, not significant

of hepatic decompensation [31, 32]. In turn, DAAs have reduced the number of patients who normally would have been waitlisted due to $\mathrm{HCV}$-associated CLD in the pre-DAA era, and DAAs have delisted an unprecedented number of LT waitlisted patients. Although a desirable public health and clinical outcome, an unintended consequence of the emergence and wide usage of DAAs has been the emergence of NASH as a leading LT etiology. It is probable that this trend will continue to balloon in the coming decades because despite the various clinical trials testing compounds for NASH therapy [33], there are no pharmacologic treatments for NASH that are as highly efficacious and effective as DAAs for HCV. Accordingly, healthcare systems and LT centers in SA and elsewhere worldwide are strongly encouraged to consider pre-emptive and novel ways to prevent, manage, and reduce NASH-associated CLD complications.

Lastly, in SA, NASH had an upward trend, while HCV showed a downward trend in patients with and without $\mathrm{HCC}$, respectively. This finding was identical to findings in the U.S., as NASH was the most rapidly increasing indication for LT in the U.S. for patients with and without HCC alike [3, 34]. It is plausible that unabated overweight, obesity, and physical inactivity epidemics in SA are underlying reasons why NASH is undiscriminating in CLD patients with and without HCC. In SA, the prevalence of overweight (70\%), obesity (35\%), and physical inactivity (35\%) are higher in adults, with a high prevalence of T2DM [35-38]. Undoubtedly, NASH is a consequence of this quadruple-prong epidemic (i.e., syndemic) 
in SA [39]. Other potential consequences can include increases in the number of donors with pre-obesity and obesity, which negatively impacts donor complications and LT outcomes for recipients. A high BMI increases the likelihood of complications in donors [40], and overweight donors are more likely to have hepatic steatosis, which is a predictor of early graft loss [41, 42]. Similarly, the high prevalence of obesity in SA has raised concerns about the possibility of forthcoming reductions in the pool of potential donors in the coming years [43]. A prospective clinical outcome study of 296 children $\leq 14$ years of age with severe obesity who underwent sleeve gastrectomy revealed that $65 \%$ of them had NASH and $60 \%$ had clinically significant fibrosis [44]. These alarming figures further highlight the impact of NAFLD on both future potential recipients and the future pool of potential donors in SA. Furthermore, the persistent metabolic disease in patients with obesity who undergo LT puts them at risk of developing NAFLD post-LT. Additionally, the reversal of the cirrhosis-related catabolic state in addition to the systemic effect of immunosuppressive agents may further worsen the metabolic abnormalities resulting in posttransplant metabolic syndrome and de novo NAFLD [45]. The current study's findings in concert with this epidemiologic backdrop suggest an urgent need for government-supported public health agencies, healthcare systems, and LT centers to target obesity as a cornerstone for the treatment of NAFLD through innovative health promotion and health education efforts. With the aim to reduce the frequency of sedentary behaviors and obesogenic eating environments as well as improving access to effective obesity treatments (to expand the pool of donors), and especially among those living with CLD (to improve LT outcomes).

Our study had notable limitations and strengths. The study only included a single LT center in SA (the largest and leading liver transplant center in the Middle East), and future iterations of this study are encouraged to include multiple LT centers and a larger cohort of LT recipients. The study was retrospective; thus, it was limited to an analysis of secondary data. All etiologies were not delineated in the study because there were a number of etiologies that were too infrequent (i.e., comprised $<2 \%$ of all LTs); and those respective etiologies were grouped together to create a non-specific composite variable (i.e., other etiologies) for statistical analysis. Nonetheless, the number of observational years and the study period were both congruent with the most recent study that published trend analyses of LT indications in the U.S. (e.g., 19 years [2001-2019] and 18 years [2002 to 2019], respectively) [3]. To our knowledge, this was the first study conducted in the Middle East that assessed and compared pre- and post-DAA LT etiology trends among LT recipients.

\section{Conclusions}

Trends in the epidemiology of LT indications among LT recipients in SA have changed. Most notably, NASH has eclipsed $\mathrm{HCV}$ in the country. This transposition was likely due to the following happening in tandem: (1) the advent of DAAs for HCV treatment in 2014, and (2) the increasing prevalence of obesity, physical inactivity, and T2DM. In a recently published Markov model, in the general SA population, NAFLD was projected to increase by $48 \%$ to $12,534,000$ cases by 2030 , and consequently, NASH to increase by $96 \%$ to $2,688,000$ cases in 2030 [46]. Assuredly, projected increases in NAFLD and NASH in the general SA population will likely trickle down to both LT donors and LT candidates. These results now call for an aggressive public health response to minimize and avert future onset of additional clinical and economic strains on health care systems and LT centers in SA.

\begin{abstract}
Abbreviations
AlH: Autoimmune hepatitis; ALD: Alcoholic liver disease; APC: Annual percentage changes; BMI: Body mass index; Cl: Confidence interval; CLD: Chronic liver disease; CVD: Cardiovascular disease; DAAs: Direct-acting antivirals; ESLD: End-stage liver disease; HBV: Hepatitis B virus; HCV: Hepatitis C virus; HCC: Hepatocellular carcinoma; IRR: Incidence rate ratio; IQR: Interquartile range; KFSHRC: King Faisal Specialist Hospital \& Research Centre; LT: Liver transplant; MELD: Model for end-stage liver disease; NAFLD: Nonalcoholic fatty liver disease; NASH: Nonalcoholic steatohepatitis; PSC: Primary sclerosing cholangitis; SA: Saudi Arabia; SCH: Schistosomiasis; SVR: Sustained viral response; T2DM: Type 2 diabetes mellitus; U.S.: United States; VH: Viral hepatitis; WMA: World Medical Association.
\end{abstract}

\section{Acknowledgements}

None.

Authors' contributions

SA Alqahtani conceived and designed the research. DCB, KIB, SA Alghamdi, SA Alabbad, AA, N Alhusseini, and N Alfaris participated in data review and manuscript preparation. FA, SA Alqahtani, and WKA took part in manuscript revision. All authors reviewed and approved the final manuscript.

Funding

The authors declare no funding.

\section{Availability of data and materials}

The datasets used and/or analyzed during the current study are available from the corresponding author on reasonable request.

\section{Declarations}

\section{Ethics approval and consent to participate}

On December 3, 2019, the Institutional Review Board of KFSHRC (Riyadh, SA) approved this study and waived the need for informed consent due to the retrospective and anonymous nature of the study (Approval Number: RAC $2,171,177)$. Authors declare that the present work was carried out in accordance with the WMA Declaration of Helsinki (adopted: 1964; last amended: 2013) and the WMA statement on measures for the prevention and fight against transplant-related crimes (adopted: October 2020). Authors also declare that no organs transplanted in the study subjects were obtained from prisoners.

Consent for publication

Not applicable. 


\section{Competing interest}

The authors declare that they have no competing interests.

\section{Author details}

${ }^{1}$ Liver Transplant Center, King Faisal Specialist Hospital \& Research Center, Riyadh, Saudi Arabia. ${ }^{2}$ Division of Gastroenterology and Hepatology, Johns Hopkins University, Baltimore, MD, USA. ${ }^{3}$ College of Medicine, Alfaisal University, Riyadh, Saudi Arabia. ${ }^{4}$ Obesity, Endocrine, and Metabolism Center, King Fahd Medical City, Riyadh, Saudi Arabia. ${ }^{5}$ Department of Medicine, Gastroenterology Section, King Faisal Specialist Hospital and Research Center, Riyadh, Saudi Arabia. ${ }^{6}$ Liver Disease Research Center, College of Medicine, King Saud University, Riyadh, Saudi Arabia.

\section{Received: 25 February 2021 Accepted: 24 May 2021}

Published online: 01 June 2021

\section{References}

1. Asrani SK, Devarbhavi H, Eaton J, Kamath PS. Burden of liver diseases in the world. J Hepatol. 2019;70(1):151-71.

2. Dolnikov S, Adam R, Cherqui D, Allard MA. Liver transplantation in elderly patients: what do we know at the beginning of 2020? Surg Today. 2020:50(6):533-9.

3. Younossi ZM, Stepanova M, Ong J, Trimble G, AlQahtani S, Younossi I, et al. Nonalcoholic steatohepatitis is the most rapidly increasing indication for liver transplantation in the United States. Clin Gastroenterol Hepatol. 2021;19(3):580-589.e5

4. Faisal N. Hepatitis $C$ and liver transplantation in direct acting antiviral era. AME Med J. 2018;3(3):40-5.

5. Belli LS, Perricone G, Adam R, Cortesi PA, Strazzabosco M, Facchetti R, et al. Impact of DAAs on liver transplantation: major effects on the evolution of indications and results. An ELITA study based on the ELTR registry. J Hepatol. 2018;69(4):810-7.

6. Adam R, Karam V, Cailliez V, O Grady JG, Mirza D, Cherqui D, et al. 2018 Annual Report of the European Liver Transplant Registry (ELTR) 50-year evolution of liver transplantation. Transplant Int. 2018;31(12):1293-317.

7. Sarwar R, Pierce N, Koppe S. Obesity and nonalcoholic fatty liver disease: current perspectives. Diabetes Metab Syndr Obes Targets Ther. 2018;11:533-42.

8. Bellentani S, Scaglioni F, Marino M, Bedogni G. Epidemiology of nonalcoholic fatty liver disease. Dig Dis. 2010;28(1):155-61.

9. (NCD-RisC) NRFC. Worldwide trends in body-mass index, underweight, overweight, and obesity from 1975 to 2016: a pooled analysis of 2416 population-based measurement studies in 128.9 million children, adolescents, and adults. Lancet. 2017;390(10113):2627-42.

10. Divella R, Mazzocca A, Daniele A, Sabbà C, Paradiso A. Obesity, nonalcoholic fatty liver disease and adipocytokines network in promotion of cancer. Int J Biol Sci. 2019;15(3):610-6.

11. Cotter TG, Rinella M. Nonalcoholic fatty liver disease 2020: the state of the disease. Gastroenterology. 2020;158(7):1851-64.

12. Lonardo A, Nascimbeni F, Ballestri S, Fairweather D, Win S, Than TA, et al. Sex differences in nonalcoholic fatty liver disease: state of the art and identification of research gaps. Hepatology. 2019;70(4):1457-69.

13. Kasper P, Martin A, Lang S, Kütting F, Goeser T, Demir M, et al. NAFLD and cardiovascular diseases: a clinical review. Clin Res Cardiol. 2020. https:// doi.org/10.1007/s00392-020-01709-7.

14. Josefsson A, Fu M, Björnsson E, Kalaitzakis E. Prevalence of pre-transplant electrocardiographic abnormalities and post-transplant cardiac events in patients with liver cirrhosis. BMC Gastroenterol. 2014;14:65.

15. Targher G, Byrne CD, Lonardo A, Zoppini G, Barbui C. Non-alcoholic fatty liver disease and risk of incident cardiovascular disease: a meta-analysis. J Hepatol. 2016;65(3):589-600.

16. Cai J, Zhang XJ, Ji YX, Zhang P, She ZG, Li H. Nonalcoholic fatty liver disease pandemic fuels the upsurge in cardiovascular diseases. Circ Res. 2020;126(5):679-704

17. Lonardo A, Leoni S, Alswat KA, Fouad Y. History of nonalcoholic fatty liver disease. Int J Mol Sci. 2020;21(16):5888.

18. Ballestri S, Mantovani A, Baldelli E, Lugari S, Maurantonio M, Nascimbeni $F$, et al. Liver fibrosis biomarkers accurately exclude advanced fibrosis and are associated with higher cardiovascular risk scores in patients with NAFLD or viral chronic liver disease. Diagnostics. 2021;11(1):98.

19. Noureddin M, Jones C, Alkhouri N, Gomez EV, Dieterich DT, Rinella ME, et al. Screening for nonalcoholic fatty liver disease in persons with type 2 diabetes in the united states is cost-effective: a comprehensive costutility analysis. Gastroenterology. 2020;159(5):1985-1987.e4.

20. Stepanova M, Henry L, Garg R, Kalwaney S, Saab S, Younossi Z. Risk of de novo post-transplant type 2 diabetes in patients undergoing liver transplant for non-alcoholic steatohepatitis. BMC Gastroenterol. 2015:15:175.

21. Jawdat M, Qattan N, Al Karawi M, Mohamed AE, Khalil H. The first liver transplant in Saudi Arabia and the Arab world. Transplant. 1992;54(4):766-7.

22. Wong RJ, Singal AK. Trends in liver disease etiology among adults awaiting liver transplantation in the United States, 2014-2019. JAMA Netw Open. 2020;3(2):e1920294.

23. Wen PH, Lu CL, Strong C, Lin YJ, Chen YL, Li CY, et al. Demographic and urbanization disparities of liver transplantation in Taiwan. Int J Environ Res Public Health. 2018;15(2):117.

24. Mathur AK, Schaubel DE, Gong Q, Guidinger MK, Merion RM. Sex-based disparities in liver transplant rates in the United States. Am J Transplant. 2011;11(7):1435-43.

25. Altraif I. Can hepatitis C virus be eliminated by 2030 ? Saudi Arabia as an example. Saudi Med J. 2018;39(8):842-5.

26. Razavi H, Blach S, Razavi-Shearer D, Alqahtani SA, Polaris Observatory Collaborators. The case for simplifying and using absolute targets for viral hepatitis elimination goals. J Viral Hepat. 2021;28(1):12-9.

27. Singal AK, Satapathy SK, Reau N, Wong R, Kuo YF. Hepatitis C remains leading indication for listings and receipt of liver transplantation for hepatocellular carcinoma. Dig Liver Dis. 2020;52(1):98-101.

28. Shirazi F, Wang J, Wong RJ. Nonalcoholic steatohepatitis becomes the leading indication for liver transplant registrants among US Adults born between 1945 and 1965. J Clin Exp Hepatol. 2020;10(1):30-6.

29. McPhail J, Sims OT, Guo Y, Wooten D, Herndon JS, Massoud OI. Fibrosis improvement in patients with HCV treated with direct-acting antivirals. Eur J Gastroenterol Hepatol. 2020. https://doi.org/10.1097/meg.00000 00000001821.

30. Facciorusso A, Del Prete V, Turco A, Buccino RV, Nacchiero MC, Muscatiello $\mathrm{N}$. Long-term liver stiffness assessment in hepatitis $C$ virus patients undergoing antiviral therapy: Results from a 5-year cohort study. J Gastroenterol Hepatol. 2018;33(4):942-9.

31. Romano J, Sims OT, Richman J, Guo Y, Matin T, Shoreibah M, et al. Resolution of ascites and hepatic encephalopathy and absence of variceal bleeding in decompensated hepatitis $C$ virus cirrhosis patients. JGH Open. 2018;2(6):317-21.

32. Calvaruso V, Cabibbo G, Cacciola I, Petta S, Madonia S, Bellia A, et al. Incidence of hepatocellular carcinoma in patients with HCV-associated cirrhosis treated with direct-acting antiviral agents. Gastroenterology. 2018;155(2):411-421.e414.

33. Noureddin M, Zhang A, Loomba R. Promising therapies for treatment of nonalcoholic steatohepatitis. Expert Opin Emerg Drugs. 2016:21(3):343-57

34. Younossi Z, Stepanova M, Ong JP, Jacobson IM, Bugianesi E, Duseja A, et al. Nonalcoholic steatohepatitis is the fastest growing cause of hepatocellular carcinoma in liver transplant candidates. Clin Gastroenterol Hepatol. 2019:17(4):748-755.e743.

35. Global-Health-Obervatory-Data. Overweight and obesity: prevalence of overweight among adults. https://www.who.int/gho/ncd/risk_factors/ overweight/en/. Accessed 18 Oct 2020.

36. Global-Health-Obervatory-Data. Prevalence of insufficient physical activity. https://www.who.int/gho/ncd/risk_factors/physical_activity_text/en/. Accessed 18 Oct 2020.

37. Obesity in Saudi Arabia in 2020: Prevalence, distribution, and its current association with various health conditions. Healthcare (Basel). 2021:9(3):311.

38. Mohamed BA, Mahfouz MS, Badr MF. Physical activity and its associated factors in females with type 2 diabetes in Riyadh, Saudi Arabia. PLoS ONE. 2020;15(10):e0239905.

39. Sanai FM, Al Khathlan A, Al Fadhli A, Jazzar AS, Hashim AM, Mansour E, et al. Clinical and economic burden of nonalcoholic steatohepatitis in Saudi Arabia, United Arab Emirates and Kuwait. Hepatol Int. 2021. https:// doi.org/10.1007/s12072-021-10182-x. 
40. Guler N, Yaprak O, Gunay Y, Dayangac M, Akyildiz M, Yuzer F, et al. Major complications of adult right lobe living liver donors. Hepatobiliary Pancreat Dis Int. 2015;14(2):150-6.

41. de Graaf EL, Kench J, Dilworth P, Shackel NA, Strasser SI, Joseph D, et al. Grade of deceased donor liver macrovesicular steatosis impacts graft and recipient outcomes more than the Donor Risk Index. J Gastroenterol Hepatol. 2012;27(3):540-6.

42. Perito ER, Rhee S, Glidden D, Roberts JP, Rosenthal P. Impact of the donor body mass index on the survival of pediatric liver transplant recipients and post-transplant obesity. Liver Transplant. 2012;18(8):930-9.

43. Al-Hamoudi W, Abaalkhail F, Bendahmash A, Allam N, Hegab B, Elsheikh $Y$, et al. The impact of metabolic syndrome and prevalent liver disease on living donor liver transplantation: a pressing need to expand the pool. Hepatol Int. 2016;10(2):347-54.

44. Alqahtani A, Elahmedi M, Alswat K, Arafah M, Fagih M, Lee J. Features of nonalcoholic steatohepatitis in severely obese children and adolescents undergoing sleeve gastrectomy. Surg Obes Relat Dis. 2017;13(9):1599-609.

45. Pais R, Barritt AS, Calmus Y, Scatton O, Runge T, Lebray P, et al. NAFLD and liver transplantation: current burden and expected challenges. J Hepatol. 2016;65(6):1245-57.

46. Alswat K, Aljumah AA, Sanai FM, Abaalkhail F, Alghamdi M, Al Hamoudi WK, et al. Nonalcoholic fatty liver disease burden-Saudi Arabia and United Arab Emirates, 2017-2030. Saudi J Gastroenterol. 2018;24(4):211-9.

\section{Publisher's Note}

Springer Nature remains neutral with regard to jurisdictional claims in published maps and institutional affiliations.
Ready to submit your research? Choose BMC and benefit from:

- fast, convenient online submission

- thorough peer review by experienced researchers in your field

- rapid publication on acceptance

- support for research data, including large and complex data types

- gold Open Access which fosters wider collaboration and increased citations

- maximum visibility for your research: over $100 \mathrm{M}$ website views per year

At BMC, research is always in progress.

Learn more biomedcentral.com/submissions 